\title{
Inovação no setor de alimentos: insetos para consumo humano
}

\author{
Food innovation: edible insects for humans
}

Innovación en el sector alimentario: insectos para humanos

Innovation dans le secteur de l'alimentation: insectes pour les êtres humains

\author{
Thelma Lucchese Cheung* \\ (thelma.lucchese@gmail.com) \\ Marília Soares Moraes* \\ (mamoraessm@gmail.com)
}

Recebido em 01/12/2015; revisado e aprovado em 03/03/2016; aceito em 30/03/2016

DOI: http://dx.doi.org/10.20435/1984-042X-2016-v.17-n.3(12)

\begin{abstract}
Resumo: Neste artigo, registrou-se a percepção de cento e trinta indivíduos sobre consumo de insetos. Aplicou-se um questionário e, através de análise de similitude, as expressões mais organizadoras das representações mentais do animal foram "não" e "nojo". A percepção dos consumidores tem função estruturante do modo como reagem aos estímulos. Conclui-se, então, que estratégias mercadológicas terão efeitos comprometidos caso não considerem os aspectos simbólicos da comida.
\end{abstract}

Palavras-chave: inovação, comportamento de consumo, insetos comestíveis

\begin{abstract}
In this article, we analyzed the percent of perception and thirty individuals about insect consumption. Applied a questionnaire and through similarity analysis expressions organizers of mental representations of the animal appeared as "no" and "disgust". The perception has structural function of the way people react to stimuli. It follows, then, that marketing strategies have committed no effects not consider the symbolic aspects of food.
\end{abstract}

Key words: innovation, food consumer behavior, edible insects

Resumen: En este artículo, analizamos el porcentaje de percepción y treinta individuos sobre el consumo de insectos. Se aplica un cuestionario ya través de expresiones de análisis de similitud de los organizadores de las representaciones mentales de los animales aparecieron como "no" y "disgusto". La percepción tiene función estructural de la forma en que la gente reacciona a los estímulos. De ello se desprende, entonces, que las estrategias de marketing han cometido ningún efecto no consideran los aspectos simbólicos de los alimentos.

Palabras clave: innovación, comportamiento del consumidor, insectos comestibles.

Résumé: Dans cet article, nous avons analysé le pour cent de la perception et trente personnes sur la consommation d'insectes. Appliquer un questionnaire et par similarité expressions d'analyse organisateurs de représentations mentales de l'animal sont apparus comme "non" et "dégoût". La perception a une fonction structurelle de la façon dont les gens réagissent à des stimuli. Il en résulte donc que les stratégies de marketing ont commis aucun effet pas tenu compte des aspects symboliques de la nourriture.

Mots-clés: innovation, comportement des consommateurs, insectes comestibles.

\section{INTRODUÇÃO}

Denomina-se entomofagia a prática de comer insetos. Sua ingestão é realizada exclusivamente por alguns animais, sendo também integrada como parte da dieta alimentar em sociedades humanas, por exemplo, em tribos da África, em diferentes países da Ásia, Austrália e da América
Latina. $\mathrm{O}$ uso de insetos como alimento humano pode acontecer pela ingestão de seus ovos, larvas, pupas, bem como do animal adulto (COSTA-NETO, 2013).

De acordo com a Organização das Nações Unidas para Agricultura e Alimentação (FAO, 2013), dois bilhões de pessoas no mundo são consumidoras de insetos. Embora seja relatado pela FAO

\footnotetext{
* Universidade Federal de Mato Grosso do Sul (UFMS), Campo Grande, Mato Grosso do Sul, Brasil.
} 
que 1900 espécies podem ser ingeridas, reconhece-se que seu potencial como alimento é pouco explorado no mundo. Para promover a entomofagia, questões nutricionais, outras relacionadas ao meio ambiente e aos aspectos sociais do cultivo poderiam nortear essa ação. Insetos representam importantes fontes de proteína e de minerais de boa qualidade; quando criados em cativeiro, apresentam excelente conversão de ração em carne para consumo (podem converter dois quilos de ração em um quilo de massa); sua produção não requer volume de água excessivo e gera menos gazes nocivos ao meio ambiente quando comparada com a de bovinos de corte. Para sua criação, não há necessidade de grandes áreas de cultivo e tampouco muito investimento em tecnologia, podendo ser uma alternativa para pequenos produtores rurais. A FAO (2013), através de um documento elaborado por pesquisadores da universidade holandesa de Wageningen, coloca a produção de insetos como um meio de pensar a alimentação humana e a segurança alimentar.

Contudo, conforme reconhecido no próprio documento realizado pela FAO (2013), o consumo de insetos, principalmente para indivíduos de muitas sociedades do ocidente, é interpretado como um tabu alimentar. Podendo ser fonte de alimento para o homem, esses animais provocam repugnância, além de serem considerados como uma prática alimentar primitiva (COSTA-NETO, 2013).

De acordo com Verbeke (2015), a aceitação do consumidor é a maior barreira para o consumo do animal como fonte segura de proteína. O autor acrescenta que, até mesmo em sociedades em que se consome insetos, o volume vem diminuindo devido à "ocidentalização" da alimentação, à mudança na dieta pela importação de alimentos baratos e de alimentos mais refinados ou processados.

Reconhecendo-se o potencial dos insetos para consumo humano e sabendo-se da possibilidade de rejeição de sua in- corporação, com destaque à campanha da FAO em 2013, interessou-se, neste artigo, em apresentar as maneiras de um grupo específico, em um dado contexto sociocultural, de classificar esses animais, segundo seus modos de pensar a incorporação desses animais em suas dietas alimentares. Para realizar reflexões aprofundadas acerca das percepções dos entrevistados, utilizou-se de alguns enfoques da sociologia e da antropologia da alimentação que explicam as escolhas alimentares a partir de dimensões de ordem social, afetiva, comportamental, cultural e ambiental.

\section{MODOS DE PERCEPÇÃO DOS ALIMENTOS COMO OBJETO DE ESTUDO}

Para compreender como o consumo doméstico e social são organizados, como os indivíduos classificam os alimentos em comestível e não comestível, quais são os costumes interiorizados nos hábitos alimentares de determinados grupos sociais, deve-se pensar as escolhas alimentares como maneiras de comunicação entre os indivíduos e seus grupos sociais. O homem é um animal onívoro que se alimenta de carne, de vegetais e dos seus símbolos (FISCHLER, 1995; RAUDE; FISCHLER, 2014). O ato alimentar comunica identidades sociais (POULAIN, 2004). Dessa forma, para entender por que um alimento pode ser facilmente aceito ou bravamente rejeitado, até entre indivíduos de uma mesma sociedade, faz-se necessário considerar que a escolha alimentar pode ser determinada tanto por aspectos biológicos, fisiológicos como, sobretudo, por aspectos culturais (o imaginário cultural, o sentido simbólico do alimento é partilhado socialmente). Para ser ingerido, o alimento deve transpassar a barreira do corpo fazendo com que tais aspectos sejam pensados e, também, incorporados por aquele que o ingeriu (POULAIN, 2004).

Dessa forma, voltando-se à questão principal deste artigo, sendo os insetos 
uma fonte de alimento presente na natureza, com valor nutritivo comprovado, quais as principais razões que fazem com que o animal não tenha status de comida para muitos consumidores?

As normas ou determinações do que é possível ser ingerido escapam de uma ordem prática, variando, até mesmo, no seio de uma mesma sociedade. Embora muitos dos consumos diários de alimentos em refeições ordinárias sejam habituais, corriqueiros ou até mesmo iguais, considerar que o ato alimentar é banal pela sua repetição implica negligenciar decisões complexas determinadas por fatores sociais que, em nada, têm a ver com conformidade ou repetições pouco reflexivas. E, em todo processo de escolha, é possível encontrar hierarquias estabelecidas pelos consumidores quanto àqueles com maior ou menor potencial de refletir a autoimagem dos indivíduos nos seus ambientes sociais (RICK; MARSHALL, 2003; CHUNYAN; BAGOZZI, 2013; BIRCH; LAWLEY, 2014).

Embora seja reconhecida a influência de um conjunto de restrições materiais sobre as escolhas alimentares, como já afirmado, age sobre os comportamentos de consumo um sistema complexo de funções sociais e simbólicas. Dessa forma, torna-se interessante considerar as interações entre as representações sociais, os modelos alimentares e os comportamentos dos indivíduos em suas decisões de consumo. Modelos alimentares consistem em um conjunto de conhecimentos acumulados de geração a geração, o qual influencia a seleção de produtos, os modos de preparo, os tipos de pratos e os rituais de consumo (RAUDE; FISCHLER, 2014). Além disso, cada modelo deve ser compreendido como um conjunto de códigos simbólicos que revelam diferentes sistemas de valores dos grupos de indivíduos de uma dada sociedade (representações sociais) e, por essa razão, tais modelos podem, por exemplo, representar uma ferramenta a serviço da saúde, do prazer e da estética (POULAIN, 2004; AURIER; SIRIEIX, 2009; CHUNYAN;
BAGOZZI, 2013; BIRCH; LAWLEY, 2014; RAUDE; FISCHLER, 2014).

Segundo menciona Lévi-Strauss (2004), para que um alimento esteja categorizado no campo do possível alimentar, ele deve ser bom para comer, para pensar e comunicar. No universo alimentar, a determinação do que é possível ser ingerido, do que realmente pode ser considerado como alimento, independe, muitas vezes, de seus aspectos nutricionais. Segundo Maciel (2013), o homem "come de tudo, mas não come tudo". O sistema de classificação daquilo que é permitido e proibido tem a ver com a cultura local, com o que é culturalmente definido como comestível. Além disso, segundo Douglas (1976), essa classificação que comunica os indivíduos nos meios aos quais eles pertencem, é capaz de estabelecer relações de distinção, de construir muros e pontes.

É através da socialização que os valores culturais, as normas, os tabus alimentares são partilhados e passam a ter sentido para os indivíduos (LANGDON; WIIK, 2010). A cultura é quem estabelece o sistema classificatório, define os horários, técnicas e os ambientes onde os alimentos poderão ser encontrados e consumidos. Por exemplo, o conceito de comida boa, forte, fraca e leve pode representar um modo de classificar, organizar e valorar os vários tipos de comida (WOORTMANN, 2008).

Considerando-se, então, que as escolhas alimentares são cheias de significados culturais e simbólicos e, tomando-se o caso dos insetos para alimentação humana, o objetivo principal deste artigo é apresentar um conjunto de informações declaradas por indivíduos habitantes da região Centro-Oeste brasileira acerca de suas percepções sobre esses animais, sobre a sua ingestão enquanto alimento potencial, ambas determinadas através e em razão de sua cultura. No tópico seguinte, materiais e métodos, constam informações sobre a coleta e o tratamento dos dados empíricos. 


\section{MATERIAL E MÉTODOS}

Baseando-se em avaliações individuais, em um grupo populacional específico, este estudo exploratório, qualitativo realizou um levantamento de dados acerca das diferentes maneiras de perceber os insetos como alimento, através de entrevista estruturada (MATTAR, 2008).

Em uma amostra não probabilística e por conveniência, 130 pessoas foram entrevistadas, todas residentes em Campo Grande, MS, e vinculadas em um mesmo ambiente de trabalho, permitindo aos investigadores a observação das suas relações sociais em contextos semelhantes. Sobre os participantes do estudo, ou amostra, decidiu-se apenas por realizar uma estratificação de gênero e de grau de instrução. Além disso, cabe informar que a média de idade foi igual a 30 anos.

Para justificar a estratificação realizada, cabem algumas citações. Conforme anteriormente citado, Fischler (1995) explica que o ser humano é onívoro e que, além de variar sua alimentação, porque não consegue extrair de um só alimento tudo o que necessita para ficar bem nutrido (como os herbívoros), os seres humanos vivem em um constante paradoxo. A necessidade de variar sua alimentação para sobreviver lhes provoca ansiedade e medo do alimento novo, desconhecido e potencialmente perigoso, gerando o que o autor chama de neofobia alimentar. Por isso, as inovações no setor de alimentos são mais bem aceitas quando os indivíduos reconhecem algo de familiar no novo produto. $\mathrm{O}$ medo do novo, a ansiedade de provar uma comida desconhecida pode variar de cultura para cultura e apresentar diferentes níveis entre grupos de indivíduos de uma mesma sociedade. Reconhecendo-se que o consumo de insetos não é familiar à população estudada, para realizar análises e comparações sobre as atitudes e percepções dos indivíduos em relação a esse produto alimentar inovador e, com isso, identificar manifestações mais ou menos neofóbicas, uma pesquisa secundária foi realizada.

De acordo com os resultados de pesquisas empíricas conduzidas em diferentes culturas ocidentais, identificou-se que não há consenso entre diferença de gênero quanto à tendência mais neofóbica (FRANK; KLAAUW, 1994; MOONEY; WALBOURN, 2001, NORDIN, 2004; MEISELMAN; KING; GILLETTE, 2010). Percebeu-se que mulheres, de modo significativamente mais importante do que os homens, tendem a experimentar mais alimentos inovadores que lhes reduzam o tempo na cozinha, que garantam bons nutrientes para o consumo da família, e demonstraram maior preocupação com o corpo, tendendo a experimentar inovações que comuniquem benefício à saúde e para o corpo. No entanto os homens ocidentais, de modo geral, inovam menos no quesito alimentos e preferem a comida tradicional, marcas conhecidas, além de darem mais prioridade ao prazer ou hedonismo alimentar (YAMAMOTO; LOPES, 2006; SANJUÁN-LÓPEZ; PHILIPPIDIS; RESANOEZCARY, 2011; GOULART; LUCCHESE-CHEUNG, 2014).

Já em outros estudos, compreendeu-se que as pesquisas sobre neofobia alimentar entre indivíduos com maior nível de escolaridade apontaram uma correlação negativa entre neofobia e titulação (FRANK; KLAAUW, 1994; MEISELMAN; KING; GILLETTE, 2010). Também conforme Lambert et al. (2005), o grau de aceitação de alimentos inovadores ou totalmente desconhecidos pelos consumidores aumenta entre aqueles que declaram graduação igual ou superior ao superior completo, e estes aceitam com maior facilidade experimentar o novo. Dessa forma, justifica-se por que foi julgado interessante entrevistar homens e mulheres que têm como grau de escolaridade o ensino superior ou titulações posteriores ao ensino de graduação.

No que concerne aos instrumentos da pesquisa, um questionário foi aplicado 
individualmente, composto por 46 questões (fechadas e abertas). Optou-se pela realização de um survey, porque o método consiste em uma busca de informação, por via de um interrogatório dos entrevistados, quanto aos seus comportamentos, atitudes, percepções, motivações, além das suas características demográficas e de estilo de vida (MALHOTRA, 2001).

Sobre as questões apresentadas aos indivíduos, ressalta-se que foi pretendido conhecer:

- as características sociodemográficas dos respondentes;

- o que os respondentes pensam sobre consumir insetos;

- a aceitação em experimentar um inseto (parte do corpo, textura do animal, modo de cozimento);

- as palavras que melhor representam o que pensaram quando se imaginaram comendo um inseto.

Em relação ao tratamento dos dados, cabe informar que as questões fechadas sobre comportamento de consumo não foram utilizadas neste artigo. A análise estatística escolhida para ser apresentada neste trabalho foi a análise de similitude, na qual foram expostas a frequência das palavras mencionadas, a ordem de citação e a conexão ou ligação entre as palavras mais representativas dos elementos de significação de suas crenças, normas sociais. Todo o tratamento através dessa análise foi realizado pelo software livre IRAMUTEQ (CAMARGO; JUSTO, 2013).

Destaca-se, também, que o que aparecerá nas árvores apresentadas deve ser compreendido como a conexão entre um grupo de declarações mais mencionado do que a média das outras declarações. As palavras, verbos ou adjetivos que poderão aparecer nas árvores com mais destaque (maiores em tamanho ou mais negritadas) indicarão que um número maior de respondentes utilizou a mesma expressão para representar sua percepção sobre a questão demandada de modo significativamente mais importante do que as de- mais. Além disso, ligadas a essas palavras centrais, as quais podem indicar como as representações estão organizadas, estão outras expressões que permitem verificar as inter-relações, ou conexão com as categorias estabelecidas (WACHELKE, 2007). Variáveis independentes foram escolhidas para caracterizar um texto.

Os resultados deste estudo fazem parte de outro maior, inserido em uma pesquisa conduzida na Univertisé de Nantes, França.

\section{RESULTADOS E DISCUSSÃO}

Quando questionados sobre o que pensavam sobre $o$ ato de consumir insetos, nas figuras 1 e 2 , percebe-se que o eixo organizador da representação é o "não", a rejeição, a atitude de repulsa. Os grafos ilustrativos das relações que se formaram entre o elemento principal da representação permitem algumas reflexões. O elemento "não" está associado a diferentes modos de perceber o consumo de insetos. Analisando-se a relação de similitude entre o "não" e a parte de baixo da árvore, constatam-se ligações importantes entre a atitude de negação e as reflexões sobre o ato de comer o animal inseto e a dificuldade de pensar sobre essa ingestão. Outra ligação, menos representativa que as mencionadas, é a de negação do consumo no Brasil. Muitos respondentes declararam que o inseto não está disseminado no Brasil como alimento e que os benefícios dessa ingestão precisam ser comprovados. Analisando-se a parte de cima da árvore, percebe-se uma relação de similitude entre o eixo "não" com os elementos "consumir proteína, ser nutritivo, interessante e, novamente, a questão cultural aparece". Termos que remetem à questão cultural parecem explicar a atitude negativa em relação ao consumo proposto pela ONU. O fato de poderem ser "nutritivos" ou uma "proteína saudável" lhes parece ser estranho, e o consumo é justificado em outras culturas. Uma ligação pouco 
representativa coloca a atitude negativa e a possibilidade do inseto ser uma alternativa para consumo futuro.

Nessa primeira árvore (Figura 1), para instrução_1, deve-se entender que a pessoa declarou ter ensino superior, instrução_2 pós-graduação lato sensu, instrução_3 mestrado e instrução_4 doutorado.
Já a codificação dos gêneros, o feminino é o_1 e o masculino é o_2. As cores que aparecem representadas indicam que pessoas que declararam ter determinado grau de escolaridade responderam de modo significativamente mais importante que o conjunto das outras certas afirmações (palavras, verbos, adjetivos).

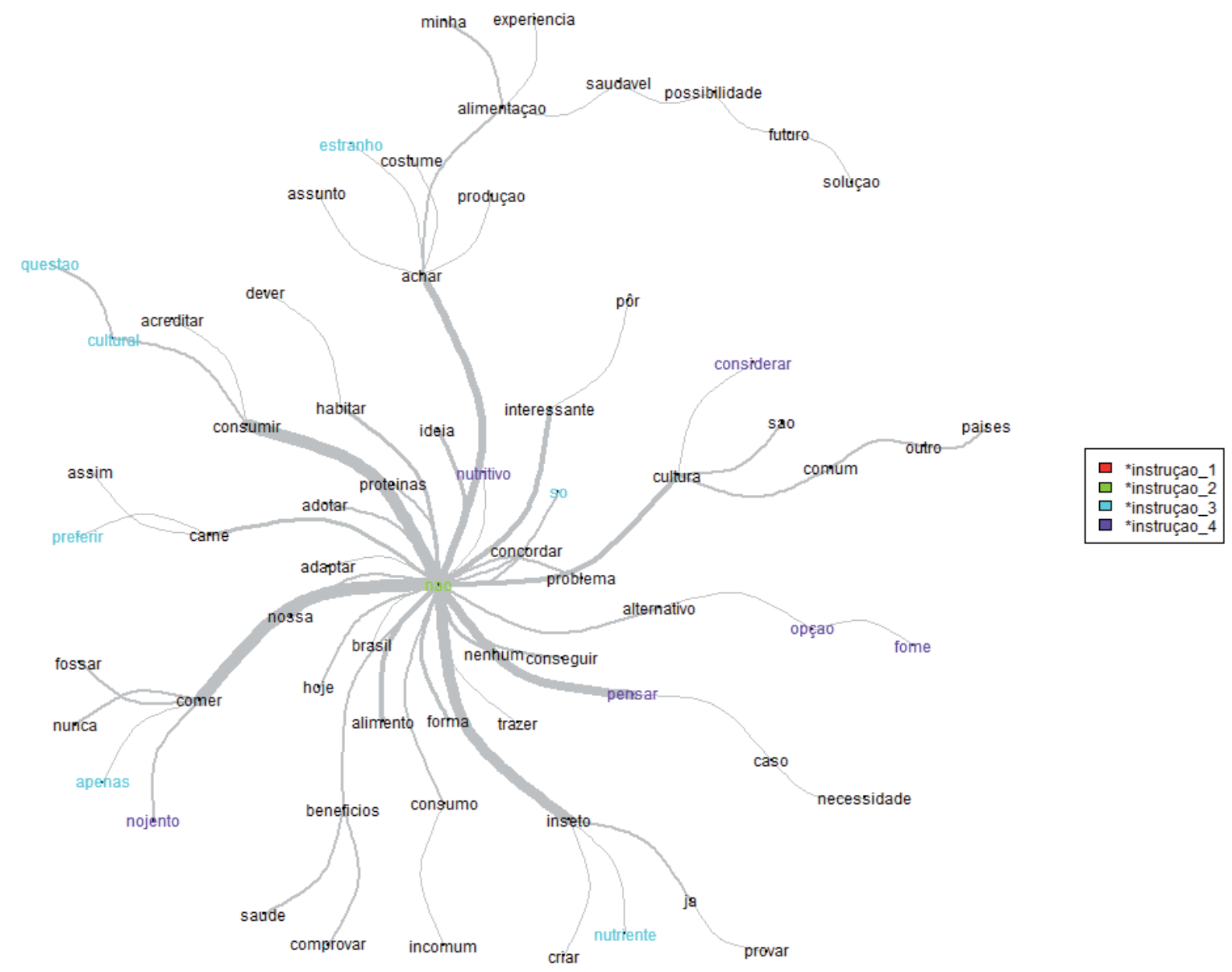

Figura 1 - Árvore de similitude referente à questão "o que você pensa sobre consumir insetos", grau de instrução como variável independente.

Fonte: Elaborada pelos autores com dados da pesquisa realizada

Conforme apresentado e justificado em metodologia, há estudos ocidentais que comprovam a relação positiva entre a titulação e a diminuição da neofobia alimentar ou interesse pelas inovações. Constatou-se que os indivíduos que declararam ter mestrado e doutorado, os níveis mais altos de graduação, revelam em suas falas as maiores repetições que associam o pensamento sobre o ato de consumir insetos (primeira pergunta realizada pelo estudo) com o verbo "preferir" ligado a carne, "estranho" e "nutrientes". Já as expressões mais representadas por um nível de escolaridade superior ao mestrado têm significados que parecem não desqualificar tanto a percepção do consumo de insetos. Embora apareça o "nojento" as outras 
referências são o "pensar", "considerar", "nutritivo", "opção" e "fome".

Quando a variável gênero é escolhida para a análise das declarações acerca do que pensam sobre o ato de consumir insetos, verifica-se, na figura 2, que a relação mais forte de similitude com o eixo organizador da percepção dos respondentes foi representada pela expressão "estranho", dita repetidamente pelo gênero feminino. Não houve expressões significativas para o gênero masculino. Assim como nos estudos em bases de dados secundárias realizados em países ocidentais, não há como afirmar alguma diferença da neofobia em relação ao consumo de insetos entre os gêneros de nossa amostra, pelo menos nessa primeira análise. Outros resultados mais interessantes aparecerão nos tratamentos das duas outras questões abertas apresentadas na sequência.

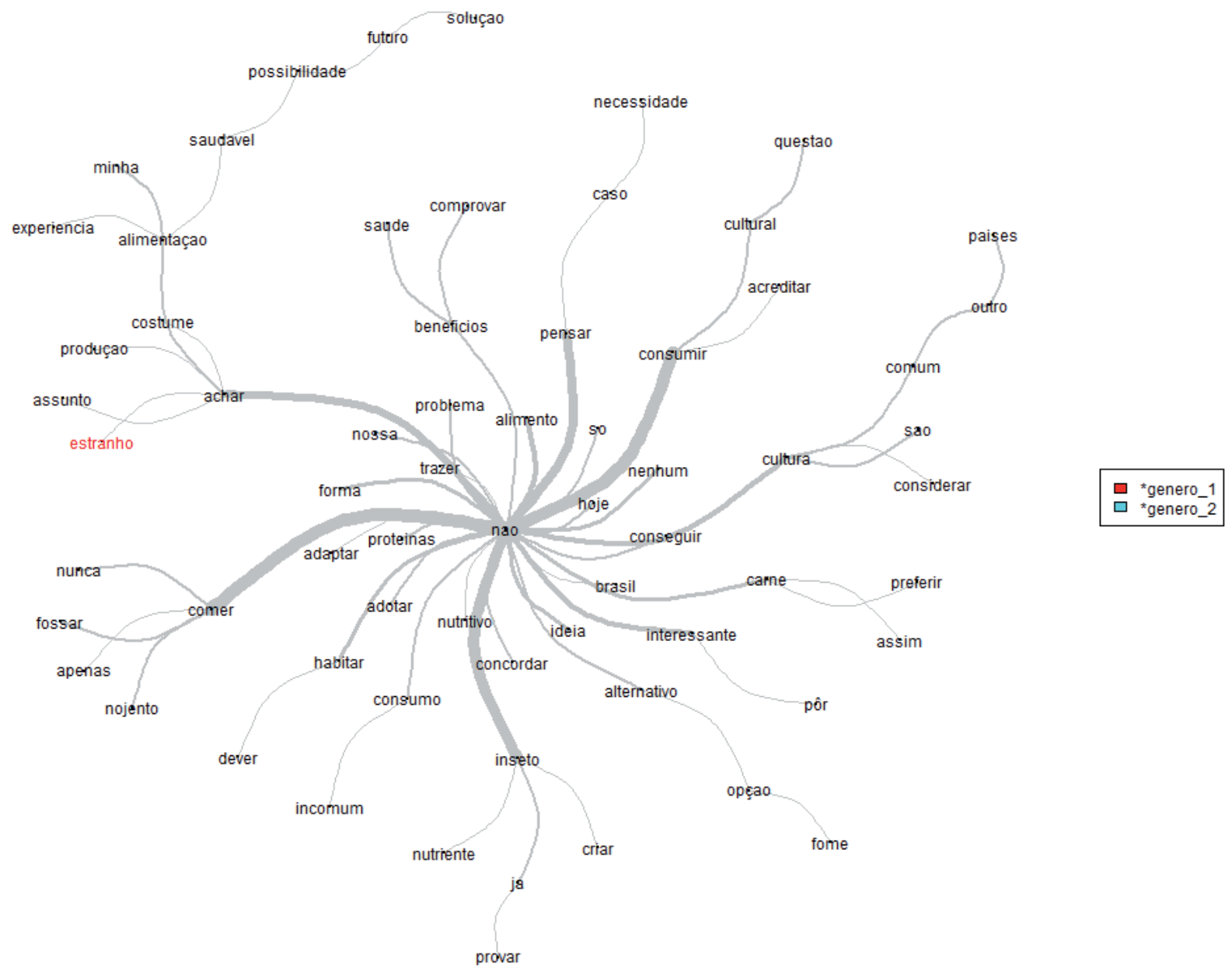

Figura 2 - Árvore de similitude referente à questão "o que você pensa sobre consumir insetos", gênero como variável independente.

Fonte: Elaborada pelos autores com dados da pesquisa realizada

Em um segundo momento das entrevistas individuais, outra pergunta lhes foi feita. Considerando-se a hipótese de que eles aceitariam ingerir insetos, pelo menos para viver a experiência, os respondentes foram instigados a pensar sobre os mo- dos de consumo e de preparo do animal, além das partes do corpo que aceitariam ingerir. Novamente, as figuras 3 e 4 apresentam variáveis grau de escolaridade e gênero como variáveis independentes que interessam à nossa análise. 


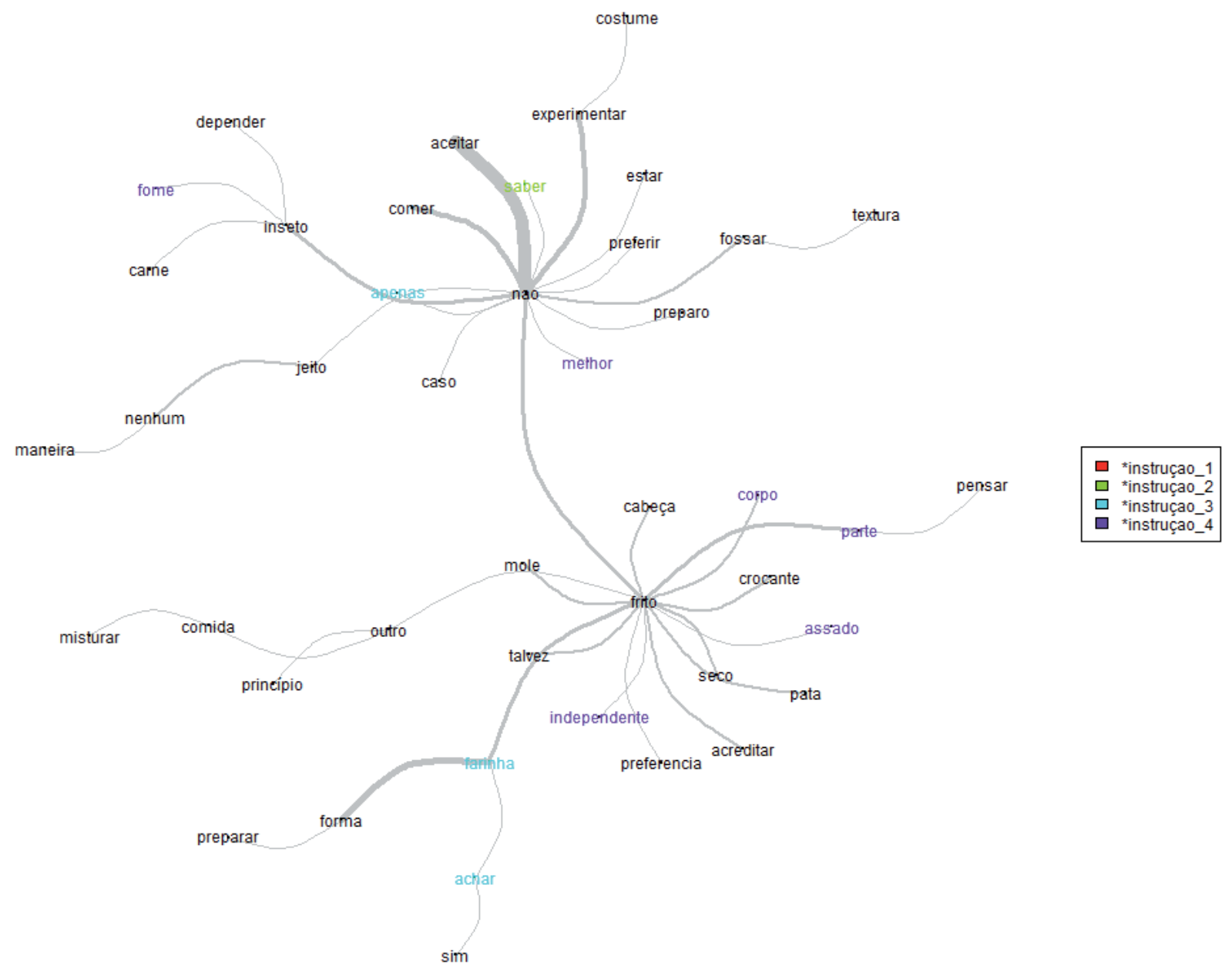

Figura 3 - Árvore de similitude referente à questão "como você aceitaria experimentar um inseto, quais as partes do corpo, modos de preparo e de cozimentos", tendo o grau de instrução como variável independente.

Fonte: Elaborada pelos autores com dados da pesquisa realizada

O modo em que os elementos responsáveis pela organização das representações, normas ou maneiras dos respondentes pensarem sobre as partes do corpo que poderiam ingerir, sobre os modos de cozimento e de preparo do animal, aparecem na figura, que ganha um outro elemento organizador. Além do elemento "não" continuar a ter um papel importante na representação do inseto como comida, essa atitude de repulsa ao pensar sobre as partes do corpo e os modos de preparo do inseto para uma experiência de consumo apresenta conexão com a impossibilidade de aceitar pensar sobre as partes, a textura e o preparo do animal. Por outro lado, o elemento "frito" aparece, tendo uma função interessante no arranjo da representação mencionada. Quando as pessoas foram entrevistadas sobre as partes do corpo e os modos de preparo, não houve consenso em negar completamente o consumo, uma vez que a maioria repetiu mais vezes que se o animal lhes for apresentado "frito" a experiência de consumo pode acontecer. No que concerne às partes do corpo, elementos como "cabeça", "pata" e o próprio "corpo" aparecem em conexidade ao elemento organizador "frito". Os entrevistados se referem a essas partes como sendo difíceis de incorporar, se a textura for "mole", a preferência é que "sejam misturados à comida". Quanto aos modos de preparo, percebe-se que aparecem como mais representativas as palavras "farinha", "assado", "crocante" e "seco". 
Ainda em relação à figura 3, dentre os indivíduos que declararam o maior grau de instrução, pôde-se visualizar uma tendência menos neofóbica em relação aos demais, uma vez que as co-ocorrências entre as palavras que organizam o elemento central "frito" foi melhor caracterizadas nas suas falas.

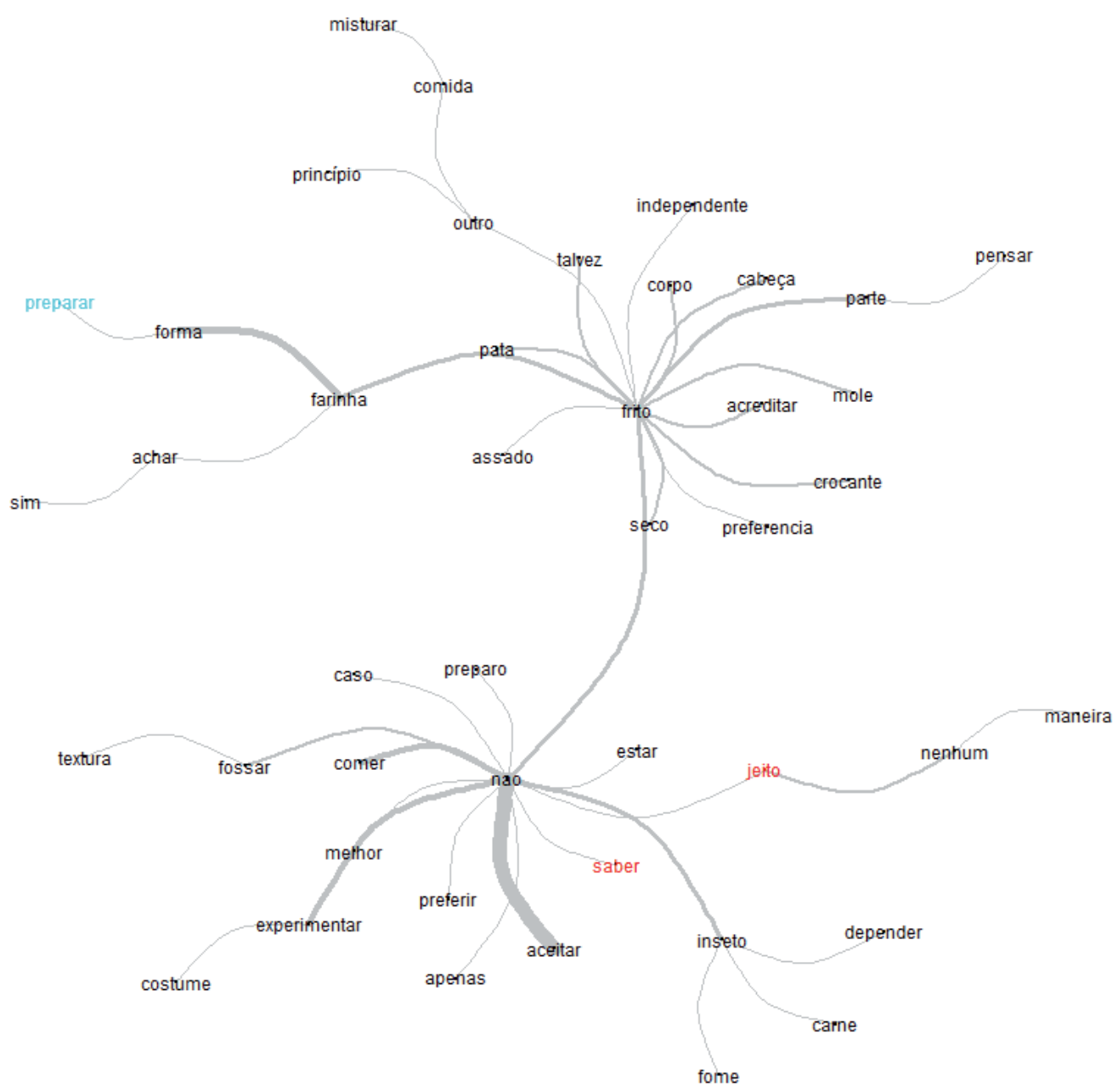

Figura 4 - Árvore de similitude referente à questão "como você aceitaria experimentar um inseto, quais as partes do corpo, modos de preparo e de cozimentos", tendo o gênero como variável independente.

Fonte: Elaborada pelos autores com dados da pesquisa realizada.

Analisando-se a figura 4, observa-se uma atitude mais neofóbica do gênero feminino em relação ao masculino, quando questionados sobre as partes do corpo que comeriam e os modos de apresentação do animal para o consumo. Em vermelho, "saber" e "jeito" aparecem como as expressões que mais representaram a fala feminina sobre essa questão. Arestas do elemento "não", as palavras parecem indicar uma atitude negativa até mesmo sobre a falta de interesse em saber como o jeito que poderiam ser preparados ou servidos. Para o gênero masculino, tem-se de modo mais importante que a média das outras palavras mencionadas a expressão "preparar", o que poderia corroborar com outros estudos ocidentais mencionados em materiais e métodos que constataram o modo de pensar masculino mais preocupado em manter tradições, receitas e menos interessados em identificar nos alimentos tradicionais muitas inovações. 
Por fim, pretendendo-se captar nas falas dos entrevistados suas emoções em relação ao que sentiram quando se ima- ginaram consumindo um inseto, foi-lhes demandado citar três palavras que melhor as representariam (ver Figuras 5 e 6).

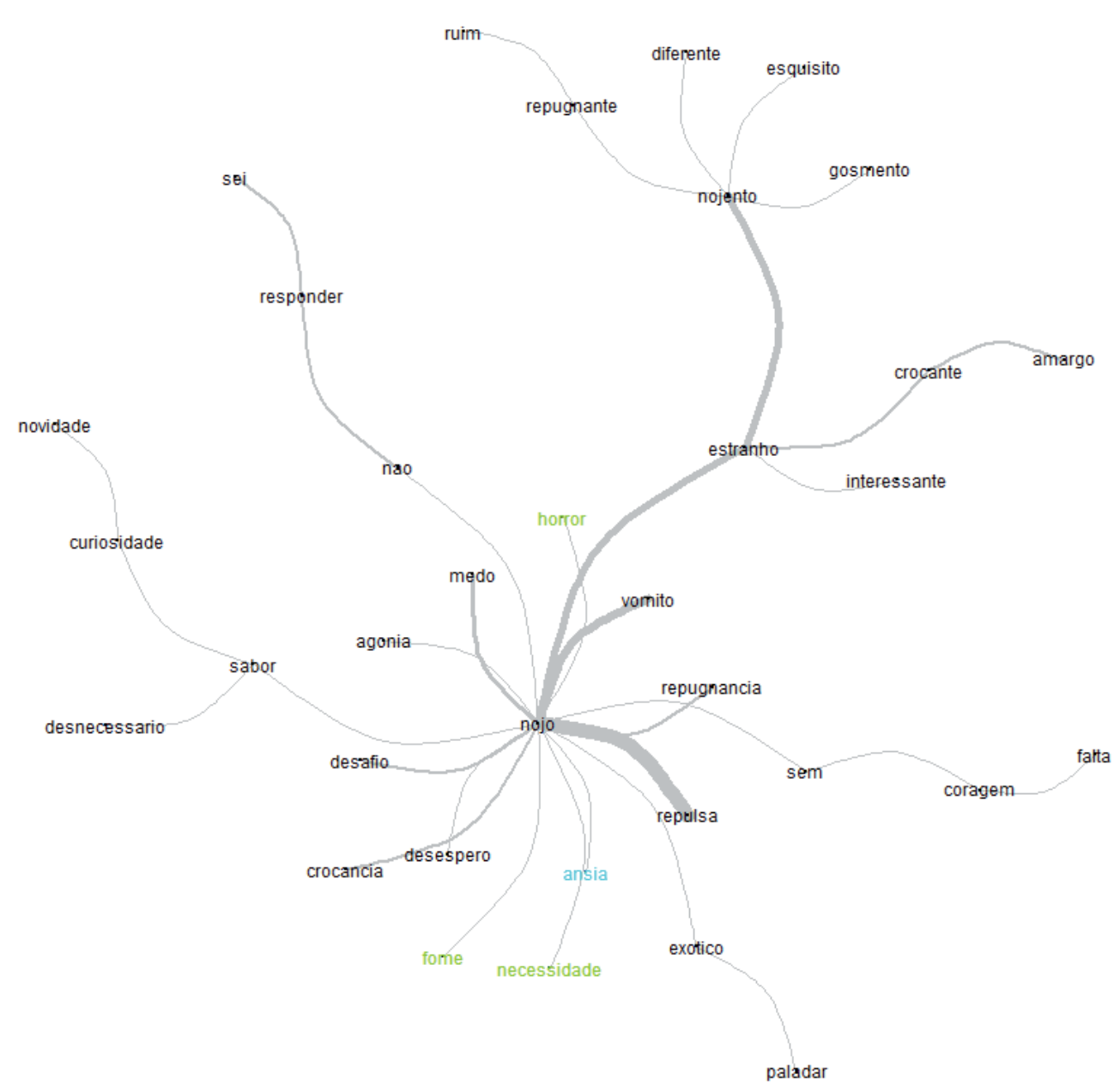

ㅊinstruçao_1

Figura 5 - Árvore de similitude referente à questão "cite palavras que melhor representam as emoções que sentiu ao pensar sobre a incorporação dos insetos", tendo o grau de formação como variável independente.

Fonte: Elaborada pelos autores com dados da pesquisa realizada

O eixo da representação das emoções foi organizado em torno da expressão "nojo". Ligadas ao eixo, percebem-se arestas significativas como "vômito, repulsa, estranho, nojento e medo", corroborando o que explicou Fischler (1995) sobre a necessidade e a dificuldade dos onívoros em inovar sua alimentação. Arestas menos representativas em hachura podem até ilustrar a fala do autor sobre o paradoxo do onívoro, que gera ansiedade alimentar, através das expressões "desafio, desespero e agonia". Contudo, também como o autor acima citado explicou, há níveis de neofobia distintos gerados pela necessidade em variar a comida. Assim, constatam-se no grupo estudado repetições de expressões que poderiam indicar um nível de neofobia menos intenso, mas não tão representativo da amostra, quando aparecem as expressões "curiosidade, novidade e interessante".

Dessa vez, os indivíduos que declararam os níveis intermediários de escolaridade se destacaram quanto ao maior nível de neofobia alimentar através das arestas 
"horror, fome, necessidade e ânsia". Fortalecem-se relações de atitudes bastantes negativas em relação às emoções do grupo quanto ao pensamento sobre a incorporação de um inseto.

Quanto à análise da árvore formada, tendo como variável o gênero, outras observações puderam ser realizadas. Enquanto que para as mulheres, de modo significativamente mais importante do que para os homens, o sentimento mais sa- liente relacionado ao eixo estruturante da representação foi a expressão "nojento", para os homens, a emoção sobressalente é destacada pela palavra "desnecessário".

Como não há consenso na literatura ocidental internacional acerca da ocorrência de atitudes mais ou menos neofóbicas manifestadas entre os gêneros, concluindo-se a fase de análise dos dados, torna-se difícil para este estudo buscar explicações teóricas para os resultados encontrados.

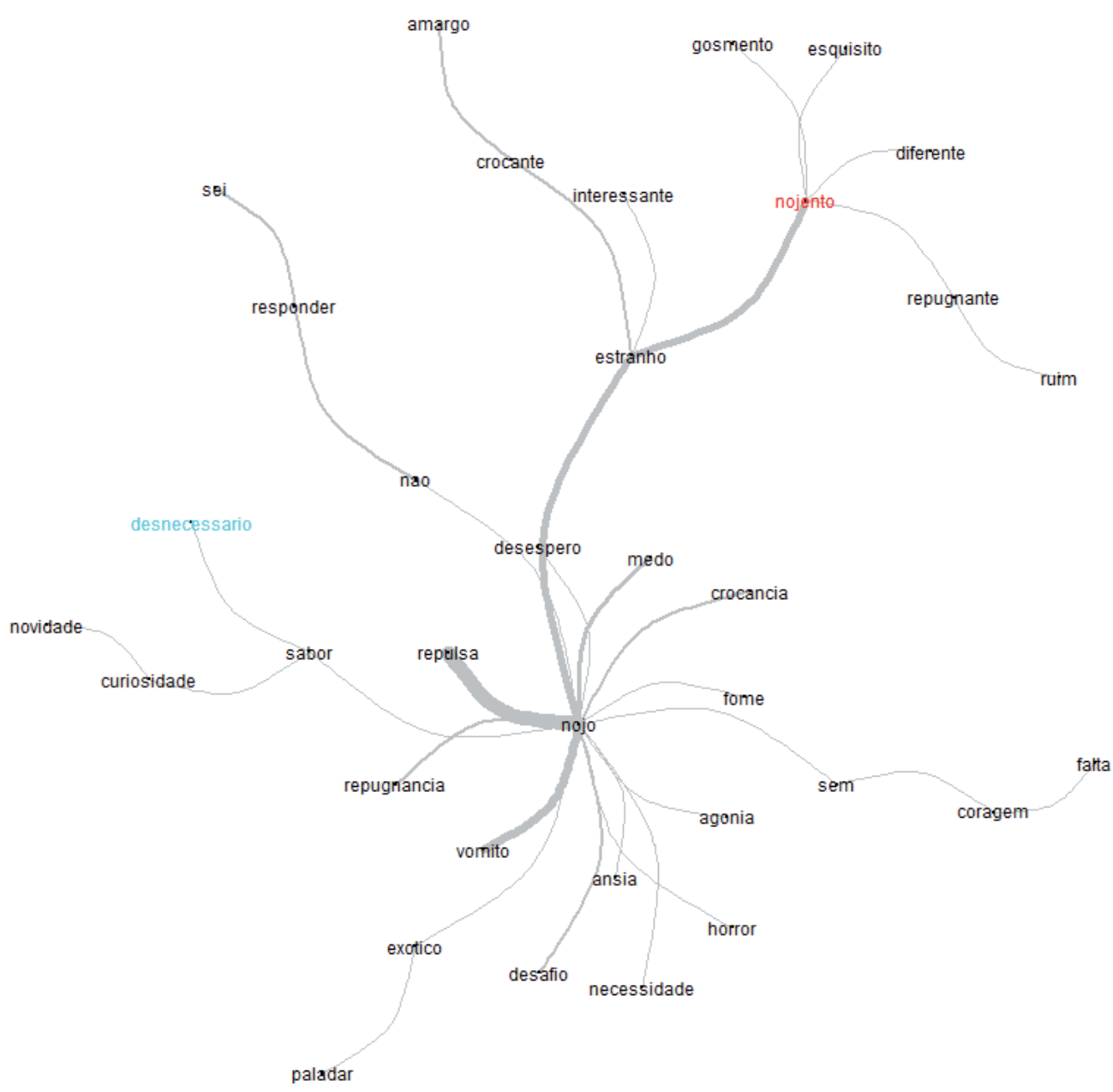

$\square$ *genero_*genero_2

Figura 6 - Árvore de similitude referente à questão "cite palavras que melhor representam as emoções que sentiu ao pensar sobre a incorporação dos insetos", tendo o gênero como variável independente.

Fonte: Elaborada pelos autores com dados da pesquisa realizada.

Por fim, cabe acrescentar que, a partir dessa análise e discussão dos resultados, percebeu-se que a função simbólica e comunicativa da comida foi exposta nas percepções do grupo social estudado. Os significados do inseto, pensado como animal e alimento, aparecem nas evocações dos indivíduos sem relação com seu valor nutritivo. A caracterização e o sentido simbólico que o animal tem para o grupo 
estudado representam suas as crenças e atitudes, aparecendo nos eixos organizadores de suas representações.

\section{CONSIDERAÇÕES FINAIS}

Conclui-se que as principais razões que fazem com que a amostra estudada não atribua o status de alimento ao inseto é a sua dificuldade em caracterizá-lo como um alimento. Através das análises de similitude, o cálculo das ligações mais fortes do elemento organizador das representações com outras expressões permitiu-nos compreender quais foram as percepções manifestadas de modo mais significativo por subgrupos, comparando-se com a amostra total do estudo. As opiniões ou expressões mais marcantes foram "não" e "nojo". Dessa forma, aos agentes do poder público e privado, interessados na produção e comercialização dos insetos como fontes de proteínas para humanos, não bastará apenas descrever às pessoas os benefícios alcançados com a criação (por exemplo, animais ricos em proteínas e minerais, produção sustentável, pegada hídrica reduzida comparada à produção de gado de corte), mas sobretudo compreender que, para serem consumidos, os alimentos devem transpassar a barreira do corpo. Dessa forma, para que os insetos sejam consumidos como alimentos, estes devem ser bons para comer e para pensar.

\section{REFERÊNCIAS}

AURIER, P.; SIRIEIX, L. Le marketing des produits agroalimentaires. 3. ed. Paris: Dunod, 2009.

BIRCH, D.; LAWLEY, M. The influence of food involvement on fish consumption: an Australian case study. In: ACADEMY OF MARKETINGCONFERENCE, MARKETING DIMENSIONS: PEOPLE, PLACES AND SPACES, 7-9 jul. 2014, Bournemouth. Anais... Bournemouth, 2014.

CAMARGO, B. V.; JUSTO, A. M. IRAMUTEQ: um software gratuito para análise de dados textuais. Temas em Psicologia, Ribeirão Preto, SP, v. 21, n. 2, p. 513-518, 2013.

CHUNYAN, X.; BAGOZZI, R. P. O. P. Cognitive, emotional, and sociocultural processes in consumption. Psychology $\mathcal{E}$ Marketing, v. 1, n. 30, p. 12-25, 2013.

COSTA-NETO, E. M. Insects as human food: na overview. Amazônica - Revista de Antropologia, Belém, v. 5, n. 3, p. 562-582, 2013.

DOUGLAS, M. Pureza e perigo. São Paulo: Editora Perspectiva, 1976. 215 p.

FISCHLER, C. El (h)ominívoro: el gusto, la cocina y el cuerpo. Barcelona: Anagrama, 1995.

FOOD AND AGRICULTURE ORGANIZATION OF THE UNITED NATIONS (FAO). Edible Insects: a solution for food and feed security, 2013. Disponível em: <http://www.fao.org/forestry / edibleinsects/en/>. Acesso em: 13 mar. 2015.

FRANK, R. A.; KLAAUW, N. V. D. The contribution of chemosensory factors to individual differences in reported food preferences. Appetite, v. 22, n. 2, p. 101-123, 1994.

GOULART, G. S.; LUCCHESE-CHEUNG, T. Alimentos inovadores: comportamentos neofóbicos e desafios para as indústrias do setor. Gestão \& Produção, São Carlos, v. 21, n. 3, p. 491-502, 2014.

LAMBERT, J. L.; BATALHA, M. O.; SPROESSER, R. L.; LAGO, A.S.; LUCCHESE, T. As principais evoluções dos comportamentos alimentares: o caso da França. Revista de Nutrição, Campinas, v. 18, n. 5, p. 577-591, 2005.

LANGDON, E. J.; WIIK, F. B. Antropologia, saúde e doença: uma introdução ao conceito de cultura aplicado às ciências da saúde. Revista Latino-Americana de Enfermagem, Ribeirão Preto, v. 18, n. 3, p. 459-66, 2010.

LÉVI-STRAUSS, C. O cru e o cozido. São Paulo: Cosac Naify, 2004. 442 p. (Mitológicas, v. I).

MACIEL, M. E.; CASTRO, H. C. A comida boa para pensar: sobre práticas, gostos e sistemas alimentares a partir de um olhar socioantropológico. Demetra, Rio de Janeiro, v. 8, Supl. 1, p. 321-328, 2013. 
MALHOTRA, N. K. Pesquisa de marketing: uma orientação aplicada. Porto Alegre: Editora Bookman, 2001.

MATTAR, J. Metodologia científica na era da informática. São Paulo: Saraiva, 2008.

MEISELMAN, H.; KING, S.; GILLETTE, M. The demographics of neophobia in a large commercial US sample. Food Quality and Preference, v. 21, n. 7, 2010.

MOONEY, K. M.; WALBOURN, L. When college students reject food: not just a matter of taste. Appetite, v. 36, n. 1, p. 41-50, 2001.

NORDIN, S. Gender differences in factors affecting rejection of food in healthy young Swedish adults. Appetite, v. 43, n. 3, p. 295301, dez. 2004.

POULAIN, J. P. Sociologias da alimentação: os comedores e o espaço social alimentar. Florianópolis: UFSC, 2004. 311 p.

RAUDE, J.; FISCHLER, C. Food Risks and Scares. Hoboken: John Wiley \& Sons, 2014. p. 567-571. (The Wiley Blackwell Encyclopedia of Health, Illness, Behavior, and Society).

RICK, B.; MARSHALL, D. W. The construct of food involvement in behavioral research: scale development and validation. Appetite, v. 40, n. 3, p. 235-244, jun. 2003.

SANJUÁN-LÓPEZ, A.; PHILIPPIDIS, G.; RESANOEZCARAY, H. How useful is acceptability to explain economic value? An application on the introduction of innovative saffron products into commercial markets. Food Quality and Preference, v. 22, n. 3, p. 255263, 2011.

VERBEKE, W. Profiling consumers who are ready to adopt insects as a meat substitute in a Western society. Food Quality and Preference, v. 1, n. 39, p. 147-155, 2015.

WACHELKE, J. F. R. Efeitos de instruções de questões abertas na ativação de elementos de representações sociais. 2007. Dissertação (Mestrado em Psicologia) - Universidade Federal de Santa Catarina, Florianópolis, Santa Catarina.

WOORTMANN, K. Quente, frio e reimoso: alimentos, corpo humano e pessoas. Caderno Espaço Feminino, Uberlândia, v. 19, n. 1, 2008.

YAMAMOTO, M. E.; LOPES, F. A. A evolução do comportamento alimentar: selecionando o que comer. FAPERN, Natal, v. 1, n. 4, p. 21-24, 2006.

\section{Sobre as autoras:}

Thelma Lucchese Cheung: Professora na Universidade Federal de Mato Grosso do Sul (UFMS). Graduação em Administração pela UFMS (2000), mestrado e doutorado em Engenharia de Produção pela Universidade Federal de São Carlos e pela Universidade de Nantes na França (fevereiro 2007 conclusão do doutorado). Tem experiência na área de Engenharia de Produção, com ênfase em Gestão de Sistemas Agroindustriais, atuando, principalmente, nos seguintes temas: marketing e o estudo do comportamento do consumidor e estudos de cadeias agroindustriais. E-mail: thelma.lucchese@gmail.com

Marília Soares Moraes: Graduação em Administração pela Universidade Federal de Mato Grosso do Sul (UFMS). E-mail: mamoraessm@gmail.com 